IV Congreso Internacional Estética y Política Poéticas del desacuerdo para una democracia plural 16 y 17 de octubre. Valencia

Doi: http://dx.doi.org/10.4995/CEP4.2019.10261

\title{
Una cuestión de amor. Bios, biopolítica, bioseguridad
}

\author{
Miguel Ángel Martínez García
}

Universitat de València - Universitat Autònoma de Barcelona

\begin{abstract}
Based on a testimony of an AIDS experience, and a corpus of artistic productions that narrate the experience of living with HIV, this text asks a basic question: How do we think about life today? What is our relationship with what is alive, with the bios?

The text is articulated from a literary resource that consists in describing a series of photographs to a reader who does not see them, but who is directed as if he did indeed see them. This imaginary series of photographs would compose, in some way, an extended family album. The commentary of these images (which includes frames of a documentary, the registration of different artistic pieces, some photographs of the family album of the author of the text or the portraits of Michel Foucault, Luc Montagnier or Donna Haraway) articulates and produces the discourse with which It brings me closer to the answers that the initial question may provoke: how do we understand life today? What effects produce our conceptions of the living? What life forms promote?

Beyond the inertia that makes us consider the other as a stranger, a danger, an object of consumption or a competitor, with this paper I bet on our ability to choose a relationship of risk, trust and love towards others. To do this, in any case, we will have to think about the apparatus (biopolitical, biomedical, security) that hinder or inhibit this choice.
\end{abstract}

Keywords: Love, Life, Bios, Biopolitics, Biosecurity, Biomedicine, Immunity, VIH, AIDS.

\section{Resumen}

A partir de un testimonio de una vivencia de sida, y de un corpus de producciones artísticas que abordan la experiencia de vivir con VIH (de "vivir con virus", como marca un texto de Marta Dillon), este texto plantea una pregunta básica: ¿cómo pensamos hoy la vida? ¿Cuál es nuestra relación con lo vivo, con la bios?

El texto se artícula a partir de un recurso literario que consiste en describir una serie de fotografías a un lector que no las ve, pero al que se dirige como si efectivamente sí las estuviera viendo. Esta serie imaginaria de fotografías compondría, de algún modo, un álbum familiar extendido. El comentario de dichas imágenes (que incluyen los fotogramas de un documental, el registro de distintas piezas artísiticas, algunas fotografías del álbum familiar del autor del texto o los retratos de Michel Foucault, Luc Montagnier o Donna Haraway) articula y produce el discurso con el que me aproximaré a las respuestas que puede suscitar la pregunta de inicio: ¿cómo entendemos la vida hoy? ¿Qué efectos producen nuestras concepciones de lo vivo? ¿Qué formas de vida resultan o se ajustan a ellas?

Más allá de la inercia que nos lleva a considerar al otro como a un extraño, un peligro, un objeto de consumo o un competidor, con este artículo apuesto por nuestra capacidad para elegir una relación de riesgo, de confianza y de amor hacia las otras. Para ello, en cualquier caso, tendremos que pensar en los dispositivos (biopolíticos, biomédicos, securitarios) que dificultan o inhiben esta elección.

Palabras clave: Amor, Vida, Bios, Biopolítica, Bioseguridad, Biomedicina, Inmunidad, VIH, Sida. 
Esta es Zulema. Mi sobrina. Tiene 24 años.

Esta es Rosa. Mi hermana. La madre de Zulema.

Esta es una fotografía de archivo de mi familia. Aquí, del lado derecho, estamos las tres: yo, cuando tenía 14 años; Zulema, en mis brazos, cuando tenía 2; y mi hermana, detrás, cuando tenía 26.

Este es Miguel. Mi ex cuñado. La ex pareja de mi hermana y el padre de Zulema. No aparece en la foto anterior. Murió en 2005, cuando Zulema tenía 10 años.

Miguel recibió el diagnóstico de VIH + en 1987, cuando yo tenía 4 años. Mi hermana lo conoció en 1989. Por tanto, en 1994, cuando se queda embarazada de Zulema, mi hermana sabía que Miguel era seropositivo. Es decir, mi hermana, conscientemente, decidió mantener relaciones sexuales con su pareja sin usar preservativo. Querían tener un bebé. Y aunque mi hermana sabía que podía contraer el virus, decidió correr ese riesgo. En ese momento, la carga viral de Miguel era mínima y ambos actuaron de un modo en que el riesgo se redujo todo lo posible. Pero lo cierto es que mi hermana decidió exponerse a una relación abierta con el virus. En el segundo intento, mi hermana se quedó embarazada. No contrajo el VIH. 9 meses después, Zulema nació sana y no había rastro del virus en su sangre.

Esta fotografía fue tomada durante el Programa de Erradicación de la Viruela que la Organización Mundial de la Salud llevó a cabo entre 1966 y 1980. Retrata, en particular, la campaña de erradicación que se desarrolló en África Occidental a finales de la década de los 60. Hasta 1967, la estrategia principal del programa fue la vacunación masiva. La viruela fue declarada oficialmente erradicada en 1980. Fue la primera enfermedad combatida a escala mundial. En la web oficial de la OMS se afirma que «este éxito extraordinario se logró gracias a la colaboración de países de todo el mundo» (OMS, 2019).

Este es Dr. Anarfi Asamoah-Baah, Director Adjunto de la Organización Mundial de la Salud. El Dr. Asamoah-Baah es el encargado de firmar el «Prefacio» de la edición de 2005 del Manual de Bioseguridad de la OMS. Los tres ejes sobre los que trabaja dicho manual son: la amenaza bioterrorista, la investigación en laboratorios y la transmisión de vectores infecciosos. La primera edición del Manual de Bioseguridad fue publicada en 1983, el año en que yo nací. Desde entonces, la bioseguridad ha cumplido una función esencial en la regulación del orden social, político y económico global.

Este es Michel Foucault. Posiblemente, el filósofo europeo más influyente de las últimas cuatro décadas. Entre otros méritos, Foucault nos ha legado el concepto de biopolítica. La biopolítica, según Foucault, remite a ese «acontecimiento decisivo» de la modernidad a través del cual la vida biológica de la población pasa a formar parte de las preocupaciones del poder (es decir: «los nacimientos y la mortalidad, el nivel de salud —o enfermedad-, la duración de la vida y la longevidad», etc.) (Foucault, 2012). A partir de este hecho, que Foucault data a mediados del siglo XVII, el poder político y el poder médico resultan indiferenciables. Foucault murió a causa del sida en 1984.

Esta es Marta Dillon. Recibió el diagnóstico de VIH + en el Hospital Ramos Mejía de Buenos Aires en 1995, el año en que nació Zulema. En octubre de ese año comenzó a escribir una columna semanal en el suplemento No del diario Página/12 bajo el título de Convivir con virus. En una de esas columnas, explica que tuvo que responder a dos cuestionarios sobre su historia clínica y, posteriormente, someterse a una exigente serie de análisis médicos para poder obtener una visa para viajar a Australia. «Esto es francamente discriminatorio», escribe. «Siento que me están tratando como si fuera sospechosa». En otra columna, narra un episodio en el que el odontólogo del Hospital Municipal le explica 
que «necesita un certificado que diga que Naná — su hija de 14 años— no tiene VIH» para poder atenderla (Dillon, 2016). Integra el colectivo feminista «Ni una menos».

Este es George Canguilhem. Médico, historiador de la ciencia, filósofo y, además, mentor de Foucault. En uno de sus libros, Escritos sobre la medicina, afirma: «Está lejos de excluirse la posibilidad de que la práctica generalizada de la vacunación tenga como consecuencia la aparición [de otras patologías]... En las sociedades industriales, donde la protección sanitaria se encuentra altamente tecnificada, la proliferación y eficacia creciente de los actos médicos... arriesga multiplicar las fallas en el sistema biológico interno de resistencia a las enfermedades» (Canguilhem, 2004).

Este es otra vez Foucault, vestido con ropa de verano. Está dictando una conferencia en la Universidad de Río de Janeiro, en octubre de 1974. En ella, Foucault continúa el argumento de Canguilhem: «Sabido es, por ejemplo, que... la lucha llevada a cabo con el mayor éxito contra los agentes infecciosos, condujo a una disminución general del umbral de sensibilidad del organismo a los agentes agresores. Ello significa que en la medida en que el organismo se sabe defender mejor, se protege, naturalmente; pero por otro lado se deja al descubierto y expuesto si se impide el contacto con los estímulos que desarrollan las defensas. De manera más general se puede afirmar que por el propio efecto de los medicamentos -efectos positivo y terapéutico- se produjo una perturbación, para no decir una destrucción, del ecosistema no solo del individuo sino de la propia especie humana. La cobertura bacilar y vírica, que constituye un riesgo, pero al mismo tiempo una protección para el organismo, con la que funcionó hasta entonces, sufre una alteración por la intervención terapéutica y queda sujeta a ataques contra los que el organismo estaba protegido» (Foucault, 1999).

Esto es una fotografía de la Universidad de Lehigh, en EE.UU. En 1987 (el año en que Miguel, mi ex cuñado, recibió el diagnóstico de VIH+). El centro de cálculo estudiantil de dicha universidad perdió una gran cantidad de datos a causa de la acción de un virus informático. El virus recibió el nombre de «sida de PC».

Este es Robert Gallo, uno de los descubridores del VIH. Ese mismo año, en 1987, escribió un artículo en The Times en el que dice lo siguiente: «El vínculo entre el Programa [de Erradicación de la Viruela en África] de la OMS y la epidemia [de sida] es una hipótesis interesante e importante. No puedo afirmar que ese vínculo, de hecho, haya existido, pero ya llevo unos años diciendo que el uso de vacunas vivas como las que se usaban para la viruela puede activar una infección latente como la del VIH» (Gallo, 1987).

Este es el artista español Pepe Espaliú, durante la acción Carrying, en 1992. El 1º de diciembre de ese año, Espaliú publicó en el diario El País un texto titulado «Retrato del artista desahuciado», en el que rechaza los procesos de exclusión a los que se ven expuestas las personas con sida. Unos meses antes realiza esta performance, Carrying, en la que recorre las calles de San Sebastián y Madrid en los brazos de una cadena de amigos y desconocidos que se turnaban para llevarlo desde el lugar en el que la acción comenzaba hasta el lugar en el que finalizaba. «El sida -escribía en El País- me ha forzado de forma radical a un estar ahí» (Espaliú, 1992). Murió a causa de dicha enfermedad un año más tarde.

Este es Luc Montagnier, el otro descubridor, junto a Robert Gallo, del VIH. En una entrevista publicada a finales de los 90, afirmaba que se debía seguir investigando cuándo y por qué la presencia del VIH en el cuerpo desencadena la enfermedad. Según Montagnier, el uso de antibióticos, muy extendido desde comienzos del siglo XX, puede ser una de las causas implicadas, a causa de los cambios que generó en el equilibrio entre el ser humano y los diferentes microorganismos de su cuerpo. Entre otros fenómenos, se han desarrollado microorganismos inmunes a los antibióticos 
conocidos, y no se descarta que algunos de ellos estén implicados en el desencadenamiento del sida (cit. en Dubcovsky, 1997).

Esto es una imagen de la campaña de prevención del sida que lanzó AIDES en 2005. Existe otra versión en la que el insecto que representa al portador y que interactúa con el humano es, en vez de una araña, un escorpión.

Este es Roberto Esposito. Un filósofo italiano que retoma el concepto de biopolítica de Foucault. Según Esposito, la idea que funciona como guía en la práctica política -biopolítica-contemporánea es la idea de inmunidad, que toma prestada de la práctica médica. Los protocolos de seguridad contra el terrorismo, las técnicas para neutralizar los virus informáticos, el refuerzo de las fronteras o los planes de prevención frente a enfermedades y epidemias convergen precisamente, según este autor, en esta categoría. Cada una de estas prácticas puede entenderse como la respuesta frente a una amenaza de intrusión, ya sea en un cuerpo electrónico, en un cuerpo político o en el cuerpo de un individuo. Ante esta posibilidad, que no es sino la posibilidad de un contagio, se responde entonces mediante la acción inmunitaria: la acción de proteger las barreras que nos separan de lo otro y de los otros (Esposito, 2005).

Esta es Zulema otra vez. Se me ha olviado deciros que hace dos años se licenció en Ciencias Biológicas. Esta semana, mientras preparaba este trabajo, mi hermana me contó algo que yo no sabía: Miguel, el padre de Zulema, estudió Telecomunicaciones porque le convencieron de que, de ese modo, aprendería una profesión con más futuro. Pero él siempre decía que tenía que haber estudiado Biología. Que quería ser biólogo. Yo no lo recuerdo. Pero entiendo que Zulema sí.

Este es Joaquim Pinto, un director de cine portugués. En 2014 dirigió E agora? Lembra-me, un cuaderno de un año de su vida con Hepatitis C y sida. En distintos momentos de la película, se muestran los incendios que están asolando la isla en la que vive junto a su marido, Nuno. En una de estas escenas, en la que aparece de fondo un bosque en llamas, nos habla, sin embargo, de su tratamiento médico y del deterioro de su salud. Como si fuera difícil distinguir el cuerpo propio del cuerpo del bosque o de la piel del planeta.

Estas son Donna Haraway y su perra Cayenne. Haraway es historiadora de la ciencia, filósofa, feminista. El último capítulo de su libro Ciencia, cyborgs y mujeres. La reinvención de la naturaleza se lo dedica al «discurso del sistema inmunitario». Aquí, escribe: «El objeto principal de mi atención será el potente y polimorfo objeto de fe, de conocimiento y de práctica llamado sistema inmunitario. Mi tesis consiste en que este es un icono elaborado para importantes sistemas de "diferencia" simbólica y material en el capitalismo tardío. Como objeto del siglo XX, el sistema inmunitario es un mapa diseñado para servir de guía en el reconocimiento y en la confusión del yo y del otro en la dialéctica de la biopolítica occidental, es decir, es un plan de acción para construir y mantener las fronteras de lo que se entiende por "el yo" y por "el otro" en el importante terreno de lo normal y de lo patológico. El sistema inmunitario es un terreno históricamente específico en el que interactúan... la política global y local, la investigación..., las producciones culturales..., la teoría estratégica militar; la práctica clínica...; las estrategias inversoras de capital de riesgo, los avances cambiantes a nivel mundial en los negocios y en la tecnología» (Haraway, 1995).

Este es otra vez Roberto Esposito. Hace un momento decía que para Esposito la idea de «inmunidad» constituye, como para Haraway, la guía de la práctica política de nuestra época. Es decir: la idea de la protección frente a lo otro y los otros. Pero Esposito da un paso más allá: para este, es justamente un exceso de protección lo que, en la actualidad, impide el desarrollo de ciertas formas de vida. De hecho, nos dice que, cuando la vida se cierra a «aquello que la circunda» y lo niega, no solo está llevando a cabo una acción defensiva, no solo está tratando de asegurar su conservación gracias a ella, sino que mediante esta acción inmunitaria puede estar al mismo tiempo «bloqueando» su desarrollo y estar colocándose así en última instancia en «riesgo de implosión»: «El proceso de inmunización —escribe- corre siempre el riesgo de 
deslizarse hacia una especie de enfermedad autoinmune que ataca el propio cuerpo que querría defender, conduciéndolo a la destrucción» (Esposito, 2005).

Este es de nuevo Luc Montagnier. Otra de las hipótesis que baraja este científico es que exista una «zona limítrofe... o... de situaciones mixtas en las cuales síndromes de inmunodeficiencia pueden presentar rasgos asimilables a patologias autoinmunes». Según Montagnier, «ese podria ser el caso del sida» (cit. en Esposito, 2005).

Este es una imagen del proyecto Anarchivo sida, que desarrollan Aimar Arriola, Nancy Garin y Linda Valdés. En la exposición con el mismo título que presentaron en Barcelona, descubrí el trabajo del artista José Osorio, del que no he encontrado fotografías en internet. En particular, el proyecto cuenta con documentación de una exposición benéfica a favor de las personas con VIH que se realiza en Guatemala en 1999 y en la que participa el artista. Durante la inauguración de esta exposición, dos enfermeras acreditadas, sin previo aviso, extraen sangre de dos cuerpos: el del propio Osorio y el de un soldado que se presenta como voluntario seropositivo. Las muestras de sangre extraídas se exponen mezcladas en un recipiente transparente.

Este es el crítico de arte y de la cultura español José Luis Brea. En 1995, escribió un artículo titulado «Sida: el cuerpo inorgánico» que dedica a la memoria de Pepe Espaliú. En este texto, Brea afirma que toda enfermedad es, de algún modo, un síntoma social y que el sida, en efecto, constituye el síntoma específico de nuestra época. La clave aquí, según Brea, es el sentido de la inmunodeficiencia. ¿Por qué? Brea la define del siguiente modo: «Inmunodeficiencia». «Incapacidad del sujeto para regenerar sus fuerzas de cohesión interna, para producir mecanismos de autodefensa», «para protegerse». «Incapacidad del sujeto para conservarse en sí». «Incapacidad del sujeto para autoproducirse». Que la enfermedad de la inmunodeficiencia adquirida constituya el síntoma social de la época contemporánea significa, según el autor, que el cuerpo deja de protegerse a sí mismo, deja de proteger su vida, porque de algún modo le es imposible vivir así, porque no acepta el lugar en el que le deja la organización social, porque ya no acepta o no le sirve la individualización, la inmunización frente a los otros y la hiperprotección frente al medio: «Es esto lo que el sida sintomatiza radicalmente escribe-, la impresencia del otro... la rotura de toda socialidad» (Brea, 2009).

Esta es la artista argentina Liliana Maresca. En 1992, Maresca realiza una instalación en el Casal de Cataluña de Buenos Aires en la que coloca un conjunto de carteles con la leyenda "ESPACIO DISPONIBLE", un número de teléfono y su nombre. Con esta acción, la artista no quiere hacer, simplemente, como han señalado los críticos, una crítica al mercado del arte. Maresca ejecuta esta pieza a principios de los 90 y cinco años después de haber recibido un diagnóstico de sida. Entonces, en vez de protegerse, a causa de la debilidad a la que le lleva la enfermedad; o de proteger a los otros del contagio, como exigían los discursos de la salud de la época; la artista se ofrece, justamente, como "ESPACIO DISPONIBLE", abierto al contacto con los otros, "APTO A TODO DESTINO".

Esta es de nuevo Donna Haraway, ahora con su pulpo de peluche. En una entrevista reciente, en la que le vuelven a preguntar por sus estudios sobre el «discurso del sistema inmunitario», afirma: «Lo que se considera yo y lo que se considera como otro es una cuestión de perspectiva o de propósito... Desde el punto de vista del parásito, el portador es como una parte de sí mismo; en cambio, desde el punto de vista del portador, el parásito parece un invasor». Sin embargo, «el portador tiene que permitir el paso de la infección. Tiene que cooperar. No hay infección si no se reconocen mutuamente. No hay relación. Y la enfermedad es una relación» (Haraway, 2018).

Este es el escritor argentino Rodolfo E. Fogwill. En 1999, publicó su cuarta novela: Vivir afuera. La acción, en ella, transcurre en un lapso de once horas, en el que seis personajes (una prostituta con VIH, un dealer o un inmunólogo) recorren distintos espacios de Buenos Aires, cruzándose ocasionalmente. El personaje principal, sin embargo, es más que cualquiera de ellos el VIH. En la novela, el virus es inseparable de ese espacio y de ese tiempo. Está constantemente presente. Circula entre los cuerpos. Toca o puede tocar a cualquiera, en cualquier momento. Es, en suma, una condición 
de vida. ¿Cómo se comportan los personajes, entonces, ante esta situación? Aquí encontramos el aspecto más significativo de la novela. Porque lo que ocurre en el texto no es que los personajes sean descritos como personas precavidas que organizan el cuidado de su salud a partir de una operación de protección, de defensa, frente a las otras personas potencialmente enfermas. Lo que sucede es, por el contrario, que los personajes establecen relaciones inciertas, de riesgo, con otros personajes, y por tanto abiertas también a una relación con el virus. En un contexto de epidemia y en una época en la que la seguridad y la salud constituyen la norma de la sociedad, la novela de Fogwill nos llama a vivir junto a los otros, entre los otros. Más allá de los miedos o las estrategias de defensa esperadas. Nos llama a vivir afuera (Fogwill, 1998).

Aquí están otra vez Zulema y mi hermana Rosa, en otra foto del archivo familiar. Les echo de menos. Pero esto no es lo importante: lo importante es que ahora, cuando miro esta foto y recuerdo su historia, pienso que es posible vivir una vida sin estar protegiéndote de los demás, de todo aquello que crees que puede ser peligroso o que puede ser una amenaza. Cuando miro esta foto, pienso que es posible establecer una relación con el otro que no se base en el miedo y la violencia. Pienso que es posible que tengamos relaciones con las demás que se sostengan en la confianza y en el amor.

\section{Referencias}

BREA, J. L. (2009). "Sida: el cuerpo inorgánico" en Brea, J. L. Un ruido secreto. El arte en la era póstuma de la cultura. [Copia de autor para descarga libre disponible en: http://joseluisbrea.net/ediciones_cc/urs.pdf.] [Consulta: 15 de septiembre de 2019]

CAnguilhem, G. (2004). Escritos sobre la medicina. Buenos Aires: Amorrortu.

Dillon, M. (2016). Vivir con virus. La Plata: EDULP.

Dubcovsky, B. (1997): “Las dudas sin aclarar” en Diario 16. 4 de abril de 1997.

Espaliú, P. (1992). "Retrato del artista desahuciado" en El País. 1 de diciembre de 1992.

Esposito, R. (2005). Immunitas. Protección y negación de la vida. Amorrortu: Buenos Aires.

FogwiLl, R. E. (1998). Vivir afuera. Buenos Aires: Sudamericana.

Foucault, M. (2012). Historia de la sexualidad I. La voluntad de saber. Madrid: Siglo XXI.

FouCAult, M. (1999). “¿Crisis de la medicina o crisis de la antimedicina?” en Foucault, M. Estrategias de poder. Obras esenciales (vol. II). Barcelona: Paidós.

GALlo, R. (1987). "Smallpox vaccine 'triggered AIDS virus"” en The Times. 11 de mayo de 1987.

HARAWAY, D. (1995). Ciencia, cyborgs y mujeres. La reinvención de la naturaleza. Valencia: Cátedra y Universidad de Valencia.

Haraway, D. (2018). Como una hoja. Una conversación con Thyrza Goodeve. Madrid: Continta me tienes.

OMS. El Programa de Erradicación de la Viruela (1966-1980). <https://www.who.int/features/2010/smallpox/es/> [Consulta: 15 de septiembre de 2019]. 